\title{
Disaggregating Asian American Cigarette and Alternative Tobacco Product Use: Results from the National Health Interview Survey (NHIS) 2006-2018
}

\author{
Manaeha Rao ${ }^{1,2}$ (D) Lilly Bar $^{1,3}$ (D) Yunnan $\mathrm{Yu}^{1,4}$ (D) Malathi Srinivasan ${ }^{1,5}$ (D) Arnab Mukherjea $^{6}$ (D) Jiang Li $^{7}$ (D) \\ Sukyung Chung ${ }^{1,8}$ (D) Siddharth Venkatraman $^{1,9}$ (D) Shozen Dan ${ }^{1,10}$ (D) - Latha Palaniappan ${ }^{1,5}$ (D)
}

Received: 3 November 2020 / Revised: 23 February 2021 / Accepted: 14 March 2021 / Published online: 28 April 2021

(C) W. Montague Cobb-NMA Health Institute 2021

\begin{abstract}
Introduction Asian Americans suffer high rates of smoking and tobacco-related deaths, varying by ethnic group. Trends of cigarette and alternative tobacco product use among Asian Americans, specifically considering ethnic group, sex, and nativity, are infrequently reported.

Methods Using National Health Interview Survey (NHIS) data from 2006-2018 and the 2016-2018 alternative tobacco supplement (e-cigarettes, cigars, smokeless tobacco, pipes), we explored cigarette and alternative tobacco product use by Asian ethnic group (Asian Indian $(n=4373)$, Chinese $(n=4736)$, Filipino $(n=4912))$ in comparison to non-Hispanic Whites (NHWs $(n$ $=275,025)$ ), adjusting for socioeconomic and demographic factors.

Results Among 289,046 adults, $12 \%$ of Filipinos were current smokers, twice the prevalence in Asian Indians and Chinese $(p<$ 0.001). The male-female gender difference was fivefold for Chinese (10.3\% vs. 2.2\%; $p<0.001)$, eightfold for Asian Indians ( $8.7 \%$ vs. $1.1 \% ; p<0.001$ ), and twofold for Filipinos (16.8\% vs. 9.0\%). Moreover, $16.3 \%$ of US-born and $10.3 \%$ of foreign-born Filipinos were current smokers. Odds of ever using e-cigarettes, cigars, smokeless tobacco, and pipes in comparison to NHWs were lowest for Chinese (ORs 0.6, 0.5, 0.2, and 0.5).

Discussion Filipinos had the highest current smoking rates of Asian ethnic groups. Though more Asian men were current smokers, the high rate of current smoking among Filipinas is concerning. More US-born Filipinos were current smokers than foreign-born, despite rates typically decreasing for US-born Asians. Investigating cultural factors contributing to less frequent use of tobacco products, such as alternative tobacco products among Chinese, may aid campaigns in curbing tobacco usage.
\end{abstract}

Keywords Asian American · Tobacco · E-cigarettes · Smoking · National Health Interview Survey

\section{Introduction}

Asian Americans are the fastest growing racial group in the USA [1], projected to surpass Hispanics as the largest immigrant group in 2055 [2], with the three most populous groups being Chinese, Asian Indians, and Filipinos [3]. Disaggregating health information pertaining to these rapidly growing populations may
Lilly Bar

lbar@stanford.edu

1 Stanford Center for Asian Health Research and Education, Stanford University School of Medicine, Stanford, CA, USA

2 Department of Neuroscience, University of Chicago, Hyde Park, IL, USA

3 Departments of Biology and Chemistry, Pomona College, Claremont, CA, USA

4 School of Computing and Information, University of Pittsburgh, Pittsburgh, PA, USA
5 Division of Primary Care and Population Health, Stanford University School of Medicine, Stanford, CA, USA

6 Department of Health Sciences, California State University, East Bay, Hayward, CA, USA

7 Center for Health Systems Research, Palo Alto Medical Foundation Research Institute, Sutter Health, Palo Alto, CA, USA

8 Quantitative Sciences Unit, Primary Care and Population Health, Stanford University School of Medicine, Stanford, CA, USA

9 Johns Hopkins School of Medicine, Baltimore, MD, USA

10 Department of Environmental and Information Science, Keio University, Tokyo, Japan 
benefit targeted public health messaging and clinical interventions.

Tobacco is a contributor to the top three Asian American causes of death: heart disease, cancer, and stroke [4, 5]. Asian ethnic groups vary in tobacco-related risk factors: rates of coronary heart disease-related deaths are high in Asian Indians [6]; lung cancer is most commonly detected in Vietnamese, yet it causes the most deaths in Chinese [7]. The most recent comprehensive study of current and ever use of tobacco among Asian-American groups reported data from 2009 to 2010; while the aggregate prevalence of current smokers among Asian Americans and Native Hawaiians/ Pacific Islanders was about $11 \%$, this percentage is misleading as the rates for subgroups ranged from $6 \%$ for Asian Indians to $19 \%$ for Japanese [8].

E-cigarette and smokeless tobacco product (SLT) use have increased in the USA since 2017 [4, 9], yet the popularity of alternative tobacco products (e-cigarettes, cigars, SLT, pipes) in Asian-American communities remains relatively unexplored. Studies examining tobacco use that utilize surveys such as the California Health Interview Survey (CHIS) [10], National Latino and Asian American Study (NLAAS) [11], and National Adult Tobacco Survey (NATS) [8] have identified heterogeneity between Asian American ethnic groups, but they do not examine alternative tobacco products. SLT is used by approximately $1.2 \%$ of Asian Americans and Native Hawaiians/ Pacific Islanders [8] and is associated with multiple mouth cancers, heart disease, and stroke, common conditions ailing AsianAmerican populations [12]. Over $40 \%$ of current young AsianAmerican SLT users regard electronic nicotine delivery systems as healthier than smoking traditional cigarettes [13].

Updated rates of cigarette and alternative tobacco product use among Asian-American ethnic groups must be reported, specifically considering gender and nativity. The smoking gender disparity is well documented in Asia. For instance, in China, the current smoking prevalence of men is about 22 times that of women [14]. In India, approximately $37 \%$ of men are current smokers compared to 5\% of women [15]. It is vital to account for this gender disparity when investigating Asian-American smoking rates. In addition, as 59\% of Asian Americans today are foreign-born $[16]^{(\mathrm{p} 1)}$, nativity status-i.e., foreign-born or US-born - is another critical factor to consider when analyzing Asian-American ethnic groups. For Asian Americans aggregate, current smoking prevalence is higher among foreign-born compared to US-born men; US-born Asian American women have a higher prevalence compared to foreign-born women [11].

Using National Health Interview Survey (NHIS) data from 2006-2018 and the 2016-2018 NHIS alternative tobacco supplement (e-cigarettes, smokeless tobacco, cigars, pipes), we explored the heterogeneity of cigarette and tobacco use for Asian-American ethnic groups (Asian Indian, Chinese, Filipino) in comparison with NHWs, by sex and nativity. Investigating recent and distinct patterns of tobacco use will aid prevention and cessation programs in instituting culturally targeted and nuanced anti-tobacco campaigns.

\section{Methods}

\section{Sample}

NHIS, conducted by the National Center for Health Statistics, is a cross-sectional nationally representative household interview survey, consisting of a generalized core section and an annually altered supplemental section [17] to understand the health and behavior of people living in the USA. NHIS is conducted in English and Spanish; participants who are not fluent in either language or do not have a translator in their household are unable to complete the survey [18]. We examined the smoking behaviors of Asian and NHW populations represented in the compiled publicly available NHIS noninstitutionalized civilian adult (18+) data from 2006 to 2018. "Asians" were disaggregated to analyze Asian-Indian, Chinese, and Filipino subgroups.

\section{Measures}

We examined cigarette use according to smoking status (current, daily, former) from 2006 to 2018 . NHIS defines a "current smoker" as one who has smoked 100 cigarettes in their lifetime and currently smokes daily or some days; a "daily smoker" is one who has smoked 100 cigarettes and smokes daily (a daily smoker is also a current smoker); a "former smoker" is one who has smoked at least 100 cigarettes in their lifetime but no longer smokes [19].

We calculated weighted current, daily, and former smoker prevalence rates in Asian Indians, Chinese, Filipinos, and NHWs, separated by sex and by nativity (US-born versus foreign-born). For current smokers, we also included trying to quit in the last year and the age at which smokers first smoked cigarettes regularly. For daily smokers, we considered the number of cigarettes smoked a day. For former smokers, we calculated the years since quitting cigarettes.

For a subset of the data from 2016 to 2018, NHIS supplement collected information on respondents' ever use of alternative tobacco products: e-cigarettes, cigars, SLT, and pipes. Ever use of e-cigarettes in the NHIS supplement refers to the use of vape pens, hookah pens, e-hookahs, e-vaporizers, and any other battery-powered device containing liquid nicotine that produces vapor. The ever use of cigars includes regular cigars, cigarillos, and little filtered cigars. The ever use of SLT includes smokeless tobacco products placed in the mouth or nose, chewing tobacco, snuff, dip, snus (SNOOSE), and dissolvable tobacco. The ever use of hookahs includes regular pipes, water pipes, and hookahs, not including electronic hookahs or e-hookahs. Weighted 
prevalence of ever use of each tobacco product were calculated for the four race-ethnic groups.

\section{Analysis}

R Studio was utilized to conduct all statistical analysis (version 1.3.959, Boston, MA). Current smoker prevalence was stratified by race-ethnic group and by sex and was plotted from 2006 to 2018 with a least-squares regression applied to each race-ethnic group. A linear regression model was used to compare smoking status (current smoker or not) to race and time. Population weights were applied to the dataset to account for the NHIS cluster sampling method, and subsequent CIs for prevalence of current, daily, and former smokers for the four race-ethnic groups were calculated. Chi-square analysis was performed to compare men to women and US-born to foreign-born respondents within each of the four race-ethnic groups. An ANOVA was applied to all continuous variables, and then Tukey's honestly significant difference (HSD) test was applied to conduct a pairwise comparison of each AsianAmerican ethnic group to NHWs. Logistic regression was performed on all dichotomous variables to generate odds of being a current smoker, daily smoker, former smoker, trying to quit in the last year, ever using e-cigarettes, ever using cigars, ever using SLT, and ever using pipes for each AsianAmerican group in comparison to NHWs. Corresponding 95\% CIs and $p$ values were generated for the ORs, controlling for age (18-44, 44-65, 65+), sex (female, male), nativity (USborn, foreign-born), family income $(<\$ 10,000$; \$10,000-\$24,000; \$25,000-\$44,000; \$45,000-\$74,000; $\$ 75,000+$ ), and highest level of education (less than high school, HS Graduate/General Equivalency Diploma (GED)/ Some College, College Degree or higher). Respondents without responses to any of the variables were excluded from analysis. This study was considered exempt by the Stanford Institutional Review Board (protocol \#57474).

\section{Results}

\section{Participants/Demographics}

Smoking behaviors were analyzed for 4373 Asian Indians, 4736 Chinese, 4912 Filipinos, and 275,025 NHW adults, for a total of 289,046 respondents. Table 1 illustrates demographic, socioeconomic, and smoking status; Fig. 1 depicts rates of current cigarette use for each of the four race-ethnic groups from 2006 to 2018. A subset of data from 2016-2018 NHIS supplement collected information on e-cigarette, cigar, SLT, and pipe ever use, including 1008 Asian Indians, 911 Chinese, 993 Filipinos, and 66,165 NHWs.

\section{Current Smoker Characteristics}

Current smoking by race/ethnicity Current smokers include $12.4 \%$ (95\% CI 11.1-14.0\%) of Filipinos, $5.1 \%$ (95\% CI 4.4-6.0\%) of Asian Indians, 5.9\% (95\% CI 5.1-7.0\%) of Chinese, and $18.5 \%$ of NHWs (95\% CI 18.1-19.0\%) (Table 1). Asian Indians and Chinese were half as likely to be a current smoker in comparison to NHWs, with ORs of 0.57 (95\% CI $0.48-0.68 ; p<0.001)$ and $0.50(95 \% \mathrm{CI}$ $0.43-0.58 ; p<0.001$ ), respectively (Table 2 ). There was no statistical difference in the rates between Filipinos and NHWs (OR 1.1; 95\% CI 0.95-1.2). Differences in smoking rates between Asian Indians and NHWs and Chinese and NHWs were found to be statistically significant; while the rate of smoking in NHWs decreased by $6.2 \%$, it only decreased by $2.3 \%$ in Asian Indians and increased by $1.1 \%$ in Chinese (Fig. 1).

Current smoking by gender For all three Asian ethnic groups, a higher percentage of men were current smokers than women. The gender difference was approximately fivefold for Chinese (10.3\% vs. $2.2 \% ; p<0.001)$, eightfold for Asian Indians $(8.7 \%$ vs. $1.1 \% ; p<0.001)$, and twofold for Filipinos (16.8\% vs. 9.0\%) (Table 3). Filipino women smoked more than other Asian female groups living in America $(p<$ 0.001).

Current smoking by nativity We found that more US-born Filipinos were current smokers than foreign-born Filipinos (16.3\% vs. $10.3 \% ; p<0.001)$ (Table 3$)$. There was no statistical difference between the US-born and foreign-born current smoking rates for Asian Indians and Chinese.

Quit attempts Asian Indian current smokers were 1.6 times more likely to try to quit within the last year (95\% CI 1.1-2.1; $p<0.05$ ) in comparison to NHWs (Table 2). There was no significant difference between Filipinos and Chinese respectively in comparison to NHWs.

Age of smoking onset Asian-Indian, Chinese, and Filipino current smokers began smoking regularly as early adults, at an average age of 21,20 , and 19 years, respectively (Table 2). On average, NHWs started smoking 3 years earlier than Asian Indians (95\% CI 2.3-4.0; $p<0.001), 2$ years earlier than Chinese (95\% CI 1.2-2.9; $p<0.001)$, and 1.5 years earlier than Filipinos (95\% CI 1.0-2.1; $p<$ 0.001) (Table 2). Respectively, Asian Indians, Chinese, and Filipinos smoked on average 6, 8, and 10 cigarettes daily (Table 2). NHW current smokers smoked an average of 7 more cigarettes a day than Asian Indians (95\% CI 5.88.8; $p<0.001$ ), 6 more than Chinese (95\% CI 4.1-7.0; $p<$ 0.001 ), and 4 more than Filipinos (95\% CI 2.9-4.9; $p<$ 0.001) (Table 2). 
Table 1 Demographic, socioeconomic, and smoking status of Asian Indian, Chinese, Filipino, and non-Hispanic Whites (NHW) in the National Health Interview Survey (NHIS), 2006-2018

\begin{tabular}{|c|c|c|c|c|c|c|c|c|c|}
\hline & & \multicolumn{2}{|c|}{ Asian Indian $(n=4373)$} & \multicolumn{2}{|c|}{ Chinese $(n=4736)$} & \multicolumn{2}{|c|}{ Filipino $(n=4912)$} & \multicolumn{2}{|c|}{ NHW $(n=275,025)$} \\
\hline & & $\begin{array}{l}\text { Weighted } \\
\%\end{array}$ & $95 \% \mathrm{CI}$ & $\begin{array}{l}\text { Weighted } \\
\%\end{array}$ & $95 \% \mathrm{CI}$ & $\begin{array}{l}\text { Weighted } \\
\%\end{array}$ & $95 \% \mathrm{CI}$ & $\begin{array}{l}\text { Weighted } \\
\%\end{array}$ & $95 \% \mathrm{CI}$ \\
\hline \multirow[t]{2}{*}{ Sex } & Female & 47.4 & $45.4-49.0$ & 54.6 & $52.8-56.0$ & 56.1 & $54.2-58.0$ & 51.3 & $51.1-52.0$ \\
\hline & Male & 52.6 & $50.5-55.0$ & 45.4 & $43.6-47.0$ & 43.9 & $42.1-46.0$ & 48.7 & $48.4-49.0$ \\
\hline \multirow[t]{2}{*}{ Place born } & US born & 8.2 & $7.1-9.0$ & 21.4 & $19.6-23.0$ & 35.1 & $32.9-37.0$ & 89.4 & $88.9-90.0$ \\
\hline & Foreign born & 91.8 & $90.6-93.0$ & 78.6 & $76.8-80.0$ & 64.9 & $62.7-67.0$ & 10.6 & $10.1-11.00$ \\
\hline \multirow[t]{3}{*}{ Age } & $18-44$ & 66.3 & $64.0-69.0$ & 54.3 & $52.1-56.0$ & 47.2 & $45.4-49.0$ & 44.6 & $44.1-45.0$ \\
\hline & $45-64$ & 25.8 & $23.9-28.0$ & 31.4 & $29.7-33.0$ & 35.8 & $34.1-38.0$ & 35.4 & $35.1-36.0$ \\
\hline & $65+$ & 7.9 & $6.8-9.0$ & 14.3 & $12.7-16.0$ & 17.0 & $15.7-18.0$ & 20.0 & $19.7-20.0$ \\
\hline \multirow{3}{*}{$\begin{array}{l}\text { Education } \\
\quad \text { level }\end{array}$} & Less than high school & 5.5 & $4.7-7.0$ & 10.6 & $9.1-12.0$ & 7.3 & $6.3-8.0$ & 11.7 & $11.4-12.0$ \\
\hline & $\begin{array}{l}\text { HS graduate/GED/some } \\
\text { college }\end{array}$ & 18.8 & $17.1-21.0$ & 26.6 & $24.8-29.0$ & 37.8 & $35.7-40.0$ & 46.2 & $45.7-47.0$ \\
\hline & College degree or higher & 75.6 & $73.5-78.0$ & 62.7 & $60.3-65.0$ & 54.9 & $52.5-57.0$ & 42.1 & $41.5-43.0$ \\
\hline \multirow[t]{5}{*}{ Family income } & $<\$ 10,000$ & 4.9 & $4.1-6.0$ & 8.6 & $7.5-10.0$ & 4.0 & $3.4-5.0$ & 5.6 & $5.3-6.0$ \\
\hline & $\$ 10,000-\$ 24,999$ & 9.4 & $8.3-11.0$ & 14.1 & $12.8-16.0$ & 9.8 & $8.9-11.0$ & 14.3 & $14.0-15.0$ \\
\hline & $\$ 25,000-\$ 44,999$ & 10.9 & $9.72-12.0$ & 16.1 & $14.7-18.0$ & 15.9 & $14.4-18.0$ & 19.0 & $18.7-19.0$ \\
\hline & $\$ 45,000-\$ 74,999$ & 18.6 & $16.9-20.0$ & 16.2 & $14.9-18.0$ & 21.3 & $19.8-23.0$ & 21.9 & $21.6-22.0$ \\
\hline & $\$ 75,000+$ & 56.3 & $54.0-59.0$ & 45.0 & $42.6-48.0$ & 49.0 & $46.7-51.0$ & 39.1 & $38.4-40.0$ \\
\hline \multirow{2}{*}{$\begin{array}{l}\text { Current } \\
\text { smoker }\end{array}$} & Yes & 5.1 & $4.39-6.00$ & 5.9 & $5.08-7.0$ & 12.4 & $11.1-14.0$ & 18.5 & $18.1-19.0$ \\
\hline & No & 94.9 & $94.0-96.0$ & 94.2 & $93.3-95.0$ & 87.6 & $86.2-89.0$ & 81.5 & $81.2-82.0$ \\
\hline \multirow[t]{2}{*}{ Daily smoker } & Yes & 3.0 & $2.49-4.0$ & 4.2 & $3.61-5.0$ & 9.3 & $8.14-11.0$ & 14.7 & $14.4-15.0$ \\
\hline & No & 97.0 & $96.3-98.0$ & 95.8 & $95.0-96.0$ & 90.7 & $89.4-92.0$ & 85.3 & $85.0-86.0$ \\
\hline \multirow{2}{*}{$\begin{array}{l}\text { Former } \\
\quad \text { smoker }\end{array}$} & Yes & 8.1 & $7.1-9.0$ & 8.9 & $7.8-10.0$ & 17.5 & $16.2-19.0$ & 24.5 & $24.2-25.0$ \\
\hline & No & 91.9 & $90.8-93.0$ & 91.1 & $89.9-92.0$ & 82.5 & $81.1-84.0$ & 75.5 & $75.2-76.0$ \\
\hline
\end{tabular}

(a)
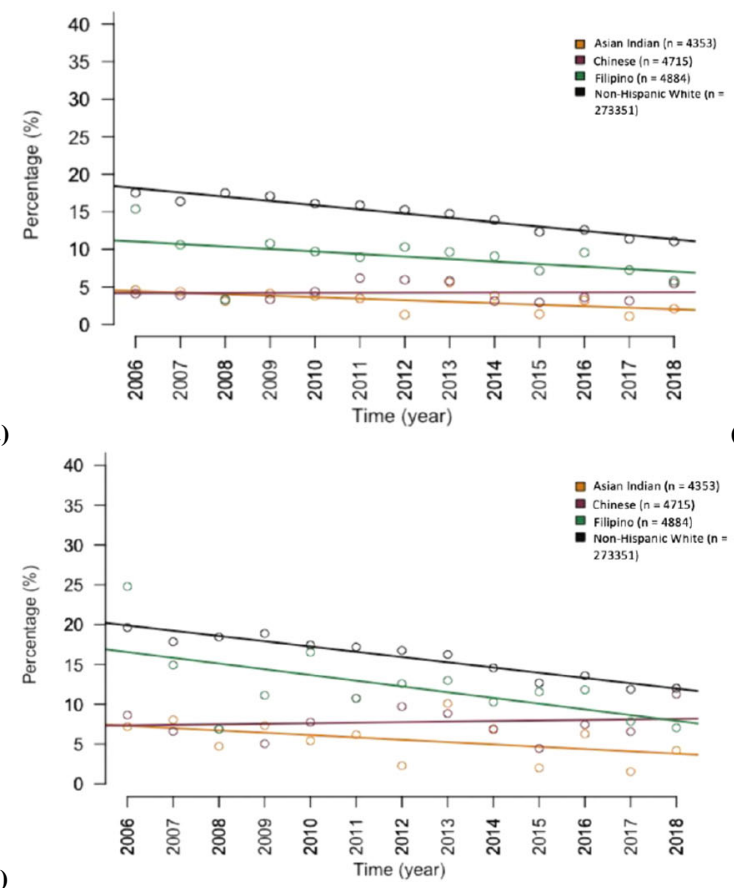

Fig. 1 Frequency of current cigarette smoking in Asian Indians, Chinese, Filipinos, and non-Hispanic Whites (NHWs) in the National Health Interview Survey (NHIS), 2006-2018. a Frequency of current cigarette smoking in Asian ethnic groups and NHWs. b Frequency of current

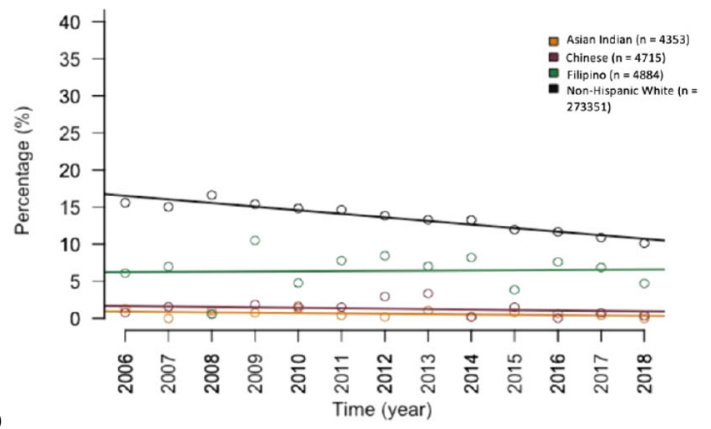

cigarette smoking in Asian ethnic groups and NHWs including only women. $\mathbf{c}$ Frequency of current cigarette smoking in Asian ethnic groups and NHWs including only men 
Table 2 Cigarette usage behaviors among Asian Indians, Chinese, and Filipinos in comparison to non-Hispanic Whites in the National Health Interview Survey (NHIS), 2006-2018

\begin{tabular}{|c|c|c|c|c|}
\hline & Asian Indian & Chinese & Filipino & Non-Hispanic White \\
\hline Current cigarette smoker & 4353 & 4715 & 4884 & 273,351 \\
\hline $\mathrm{n}$ & $0.58 * *(0.48-0.68)$ & $0.50 * *(0.43-0.58)$ & $1.07(0.95-1.20)$ & - \\
\hline \multicolumn{5}{|l|}{ OR $(95 \% \mathrm{CI})$} \\
\hline Daily cigarette smoker & 4353 & 4715 & 4884 & 273,351 \\
\hline \multicolumn{5}{|l|}{ OR $(95 \% \mathrm{CI})$} \\
\hline Former cigarette smoker & 4353 & 4715 & 4884 & 273,351 \\
\hline \multicolumn{5}{|l|}{ OR $(95 \% \mathrm{CI})$} \\
\hline Try to quit in the last year (current smokers only) & 275 & 301 & 644 & 50,379 \\
\hline \multicolumn{5}{|l|}{ OR $(95 \% \mathrm{CI})$} \\
\hline Age first smoked regularly (current smokers) & 20.7 & 19.6 & 19.1 & 17.5 \\
\hline Mean (years) & $3.2 * *(2.3-4.0)$ & $2.0 * *(1.2-2.9)$ & $1.5 * *(1.0-2.1)$ & - \\
\hline \multicolumn{5}{|l|}{ Difference in comparison to NHW $(95 \% \mathrm{CI})$} \\
\hline Number of cigarettes smoked daily (current smokers) & 6.3 & 8.1 & 9.7 & 13.6 \\
\hline Mean (number of cigarettes) & $7.3 * *(5.8-8.8)$ & $5.6^{* *}(4.1-7.0)$ & $3.9 * *(2.9-4.9)$ & - \\
\hline \multicolumn{5}{|l|}{ Difference in comparison to NHW (95\% CI) } \\
\hline Number of cigarettes smoked daily (daily smokers) & 8.6 & 9.8 & 11.6 & 15.9 \\
\hline Mean (number of cigarettes) & $7.3 * *(5.4-9.2)$ & $6.0 * *(4.4-7.6)$ & $4.3 * *(3.2-5.3)$ & - \\
\hline \multicolumn{5}{|l|}{ Difference in comparison to NHW (95\% CI) } \\
\hline Years since quitting cigarettes (former smokers) & 11.4 & 16.5 & 15.9 & 18.4 \\
\hline Mean (years) & $7.0 * *(4.9-9.1)$ & $1.9 *(0.02-3.9)$ & $2.5 * *(1.1-3.8)$ & - \\
\hline
\end{tabular}

Displayed are ORs for being a current, daily, or former cigarette smoker, and for trying to quit in the last year (current smokers only), controlling for age, sex, nativity, education, and income. Age first smoked regularly, number of cigarettes smoked daily, number of cigarettes smoked daily, and years since quitting were analyzed with Tukey's honestly significant difference (HSD) to conduct a pairwise comparison of each Asian ethnic group to NHWs

$* * p<0.001, * p<0.05$

\section{Daily Smoker Characteristics}

Daily smoking by race/ethnicity $9.3 \%$ (95\% CI 8.1-11.0) of Filipinos, $4.2 \%$ (95\% CI 3.6-5.0) of Chinese, and 3.0\% (95\% CI 2.5-4.0) of Asian Indians were daily smokers (Table 1). The odds of Asian Indians and Chinese to be daily smokers were a little more than half that of NHWs, with respective ORs of 0.6 (95\% CI $0.45-0.69 ; p<0.001)$ and 0.6 (95\% CI 0.46-0.66; $p<$ 0.001 ) (Table 2). The odds of being a daily smoker for Filipinos, in comparison to NHWs, were not statistically different. Respectively, Asian Indian, Chinese, and Filipino daily smokers smoked an average of 9, 10, and 12 cigarettes daily (Table 2). NHW daily smokers smoked an average of 7 more cigarettes than Asian Indians (95\% CI 5.4-9.2; $p<0.001), 6$ more than Chinese (95\% CI 4.4-7.6; $p<0.001$ ), and 4 more than Filipinos (95\% CI 3.2-5.3; $p<0.001$ ) (Table 2).

Daily smoking by gender A larger proportion of men in all Asian-American ethnic groups were daily smokers compared to women. Moreover, $12.6 \%$ of Filipino men and $6.8 \%$ of Filipino women were daily smokers $(p<0.001) ; 7.8 \%$ of Chinese men and $1.3 \%$ of Chinese women were daily smokers $(p<0.001) ; 5.3 \%$ of Asian-Indian men and $0.6 \%$ of AsianIndian women were daily smokers $(p<0.001)$ (Table 3 ).
Daily smoking by nativity $12.6 \%$ of US-born Filipinos and $7.5 \%$ of foreign-born Filipinos were daily smokers $(p<$ 0.001) (Table 3). Asian Indians and Chinese had no statistical difference in daily smoking rates between US- and foreignborn groups.

\section{Former Smoker Characteristics}

Former smoker by race/ethnicity $17.5 \%$ (95\% CI 16.2-19.0) of Filipinos, 8.9\% (95\% CI 7.8-10.0) of Chinese, and 8.1\% (95\% CI 7.1-9.0) of Asian Indians were former smokers (Table 1). Compared to NHWs, the odds of Filipinos, Asian Indians, and Chinese being a former smoker (including non-smokers) were 0.8 (95\% CI $0.70-0.84 ; p<0.001), 0.4$ (95\% CI $0.34-0.46 ; p<$ 0.001 ), and 0.4 (95\% CI $0.33-0.45 ; p<0.001$ ), respectively (Table 2).

Former smoker by nativity More US-born Filipinos $(20.1 \% ; p<0.001)$ were former smokers than foreignborn $(16.1 \% ; p<0.001)$ (Table 3$)$. There was no statistical difference between US- and foreign-born former smokers for Asian Indians and Chinese. 
Table 3 Smoker status prevalence of Asian Indians, Chinese, Filipinos, and non-Hispanic Whites in the National Health Interview Survey (NHIS), 2006-2018, by sex and place born

\begin{tabular}{|c|c|c|c|c|c|c|c|c|}
\hline & \multicolumn{2}{|l|}{ Asian Indian } & \multicolumn{2}{|l|}{ Chinese } & \multicolumn{2}{|l|}{ Filipino } & \multicolumn{2}{|c|}{ Non-Hispanic White } \\
\hline \multicolumn{9}{|l|}{ Sex } \\
\hline & $\begin{array}{c}\text { Female }(n= \\
1944)\end{array}$ & $\begin{array}{c}\text { Male }(n= \\
2409)\end{array}$ & $\begin{array}{c}\text { Female }(n= \\
2561)\end{array}$ & $\begin{array}{c}\text { Male }(n= \\
2154)\end{array}$ & $\begin{array}{c}\text { Female }(n= \\
2821)\end{array}$ & $\begin{array}{c}\text { Male }(n= \\
2063)\end{array}$ & $\begin{array}{c}\text { Female }(n= \\
149,191)\end{array}$ & $\begin{array}{l}\text { Male }(n= \\
\quad 124,160)\end{array}$ \\
\hline $\begin{array}{l}\text { Current } \\
\text { smoker } \%\end{array}$ & $1.1 * *$ & $8.7 * *$ & $2.2 * *$ & $10.3^{* *}$ & $9.0 * *$ & $16.8^{* *}$ & $16.8 * *$ & $20.2 * *$ \\
\hline $\begin{array}{l}\text { Daily smoker } \\
\quad \%\end{array}$ & $0.6^{* *}$ & $5.3^{* *}$ & $1.3^{* *}$ & $7.8 * *$ & $6.8 * *$ & $12.6^{* *}$ & $13.6^{* *}$ & $15.9 * *$ \\
\hline \multirow{3}{*}{$\begin{array}{l}\text { Former } \\
\text { smoker \% } \\
\text { Place born }\end{array}$} & $1.4 * *$ & $14.1 * *$ & $3.8 * *$ & $15.0 * *$ & $9.9 * *$ & $27.2^{* *}$ & $21.6 * *$ & $27.6^{* *}$ \\
\hline & & & & & & & & \\
\hline & $\begin{array}{l}\text { Foreign born }(n= \\
\text { 3957) }\end{array}$ & $\begin{array}{l}\text { US born }(n= \\
388)\end{array}$ & $\begin{array}{l}\text { Foreign born }(n= \\
\text { 3713) }\end{array}$ & $\begin{array}{l}\text { US born }(n= \\
996)\end{array}$ & $\begin{array}{l}\text { Foreign born }(\mathrm{n}= \\
\quad 3105)\end{array}$ & $\begin{array}{l}\text { US born }(n= \\
1770)\end{array}$ & $\begin{array}{l}\text { Foreign born }(n= \\
\quad 30,769)\end{array}$ & $\begin{array}{c}\text { US born }(n= \\
242,496)\end{array}$ \\
\hline $\begin{array}{l}\text { Current } \\
\quad \text { smoker } \%\end{array}$ & 5.1 & 5.0 & 6.1 & 4.6 & $10.3 * *$ & $16.3 * *$ & $11.9 * *$ & $19.3 * *$ \\
\hline $\begin{array}{l}\text { Daily smoker } \\
\quad \%\end{array}$ & 3.0 & 3.7 & 4.6 & 2.8 & $7.5^{* *}$ & $12.6^{* *}$ & $7.8 * *$ & $15.5^{* *}$ \\
\hline $\begin{array}{l}\text { Former } \\
\quad \text { smoker } \%\end{array}$ & 8.2 & 6.6 & 8.6 & 9.8 & $16.1 *$ & $20.1 *$ & $19.3 * *$ & $25.1 * *$ \\
\hline
\end{tabular}

Chi-square significance tests conducted for each row

$* * p<0.001, * p<0.05$

Years since quitting When looking at the time since former smokers quit cigarettes, Chinese quit an average of 1.9 years (95\% CI 0.02-3.9; $p<0.05$ ) later than NHWs. Filipinos quit an average of 2.5 years (95\% CI 1.1-3.8; $p<0.001$ ) later than NHWs, while Asian Indians quit about 7 years (95\% CI 4.99.1; $p<0.001$ ) later (Table 2).

\section{Discussion}

Highlights While smoking rates have generally decreased among Asian Indians, Chinese, Filipinos, and non-Hispanic Whites from 2006 to 2018, the decrease seen in Asian Indians and Chinese was statistically less than the decrease seen in NHWs. Filipino Americans have double the smoking rates of Asian-Indian and Chinese Americans. While more Asian males across the three ethnic groups were current smokers, Filipino women have four to eight times the current smoking rate of the other Asian groups, standing out as a point of concern. More US-born Filipinos were current smokers despite the fact that for Asian Americans aggregate, more foreign-born are current smokers. Chinese Americans were consistently less likely to use alternative tobacco products in comparison to NHWs. Asian Indians are an ideal group to consider when identifying protective factors that can contribute to low rates of tobacco usage.

\section{Cigarettes}

Twice as many Filipinos were current smokers compared to Asian Indians and Chinese, and three times as many US-born
Filipinos were current smokers compared to US-born Asian Indians and Chinese. Filipinos had a current smoking prevalence rate higher than the current aggregated rate for all Asian Americans, 7.1\% [20], emphasizing this population's need for additional attention by cessation services. However, most Asian resources focus on Chinese, Koreans, and Vietnamese [21], with little to no culturally tailored anti-smoking resources available for Filipinos. When surveying FilipinoAmerican men proficient in English, the majority preferred smoking cessation resources in Tagalog or a mix of Tagalog and English [22]. The main National Smoking Quitline for Asians only provides aid in Cantonese, Mandarin, Korean, and Vietnamese [20], overlooking Tagalog — and the highrisk Filipino population-completely.

Furthermore, our findings showcase a concerning proportion of Filipino women as current smokers (9\%). The gender difference for the Filipino group is worrisome, as only two times as many men were current smokers compared to women, a stark contrast to the larger gender disparity seen in Asian Indians and Chinese. While daily smoking has been decreasing broadly, light and intermittent smoking has been increasing in minority groups, especially female minority groups [23]. However, of the Filipino women classified as current smokers, $75 \%$ were daily smokers, not just light or intermittent smokers. As daily smokers are the most susceptible to the harmful effects of tobacco and have lower motivation to quit compared to intermittent smokers [24], interventions for Filipino women must be tailored to address daily smoking.

Filipinos did not follow the aggregate Asian trend of lower smoking among US-born, reflecting literature showcasing that for Chinese, Japanese, Korean, and Vietnamese-but not 
Filipino-American men, more years spent living in the USA is associated with low rates of current smoking [25]. Our results confirm that various acculturation factors likely affect the smoking behavior of specific Asian-American ethnic groups differently [25]. As evidenced by our observations of smoking in Filipino Americans, generalized hypotheses related to Asians must be revisited and researched for specific Asian-American groups.

The Centers for Disease Control and Prevention (CDC) and Asian Smokers Quitline provide many cessation resources for Chinese Americans in Mandarin and Cantonese [26], including in-language pamphlets on reasons to quit, creating a quit plan, and managing cravings [20]. Despite these resources and attention from the $\mathrm{CDC}$ on states with high Chinese populations, current smoking rates in Chinese men were found to be considerably higher than in 2010 [8]. Implementing social-network family-focused interventions in Chinese and Vietnamese American households were extremely successful in increasing learning about tobacco health risks, cessation, and communications between the smoker and their family [27]. To decrease current smoking in Chinese men specifically, active dyadic and familial interventions may be superior to in-language passive smoking cessation resources alone.

Our findings for current smoking in Asian Indians were largely consistent with the previously established rates [8]. In our sample, Asian Indians were 50\% more likely to try to make a genuine quit attempt in the last year in comparison to NHWs, and intention to quit is a critical stage on the path to cessation [28]. Protective factors that play into their lower prevalence and higher quit attempt rates can be investigated and potentially utilized to aid higher-risk groups. For instance, it has been hypothesized that religiosity protects many Asian Indians from smoking [29].

\section{Alternative Tobacco Products}

We examined ever use of alternative tobacco products by Asian-American ethnic group and NHW respondents, based on the available questions in the NHIS supplement (Table 4). While participant responses display current alternative tobacco product (ATP) use, we could not characterize detailed current and every day use or participants' mindset/motivations. Future research must include measures of consistent or everyday ATP use in America, as a one-time use of an e-cigarette, SLT, or cigar would qualify the respondent as an ATP user in the NHIS supplement.

Importantly, Chinese had consistently lower odds of ever use of ATP in comparison to NHWs. Investigating why Chinese Americans are less likely to ever engage in these ATPs may provide insight into interventions that may limit ATP use in young NHWs and Hispanics, populations at a higher risk to use more routinely [30].

Our ATP findings revealed that Filipinos were two times as likely to have ever used e-cigarettes compared to Asian Indians and Chinese. Ever use of cigars was very high for all Asian groups (10.3-17.8\%), conflicting with other studies that demonstrate the current use prevalence for these three groups
Table 4 Prevalence and odds of ever use of alternative tobacco products for Asian Indians, Chinese, and Filipinos in comparison to non-Hispanic Whites in the National Health Interview Survey (NHIS), 2006 2018

\begin{tabular}{|c|c|c|c|c|}
\hline & Asian Indian & Chinese & Filipino & NHW \\
\hline \multicolumn{5}{|l|}{ E-cigarettes } \\
\hline$\% * *$ & 5.8 & 6.1 & 12.1 & 16.1 \\
\hline $\mathrm{n}$ & 1005 & 909 & 991 & 65,975 \\
\hline OR $(95 \% \mathrm{CI})$ & $0.74(0.53-1.03)$ & $0.58^{*}(0.40-0.84)$ & $1.26(0.95-1.67)$ & - \\
\hline \multicolumn{5}{|l|}{ Cigars } \\
\hline$\% * *$ & 10.3 & 11.6 & 17.8 & 30.8 \\
\hline $\mathrm{n}$ & 1005 & 907 & 990 & 65,929 \\
\hline OR $(95 \% \mathrm{CI})$ & $0.43 * *(0.32-0.57)$ & $0.48 * *(0.34-0.66)$ & $0.75 *(0.60-0.95)$ & - \\
\hline \multicolumn{5}{|c|}{ Smokeless tobacco product } \\
\hline$\% * *$ & 2.5 & 1.2 & 4.2 & 12.3 \\
\hline $\mathrm{n}$ & 1005 & 908 & 991 & 65,952 \\
\hline OR $(95 \% \mathrm{CI})$ & $0.54 *(0.29-1.01)$ & $0.15 * *(0.07-0.33)$ & $0.57 *(0.38-0.85)$ & - \\
\hline \multicolumn{5}{|l|}{ Pipe } \\
\hline$\% * *$ & 5.9 & 6.0 & 8.9 & 15.0 \\
\hline $\mathrm{n}$ & 1005 & 909 & 991 & 65,943 \\
\hline OR $(95 \% \mathrm{CI})$ & $0.58 * *(0.43-0.79)$ & $0.52 * *(0.36-0.74)$ & $0.85(0.62-1.15)$ & - \\
\hline
\end{tabular}

Displayed are ORs for ever having used e-cigarettes, cigars, smokeless tobacco product, and pipes for each Asian ethnic group and NHWs, controlling for age, sex, nativity, education, and income

$* * p<0.001, * p<0.05$ 
to be $1-3 \%$ [8]. Notably, the only instance of Asian Indians surpassing Chinese in ATP ever use was with SLT. Among Asian Indians, cultural SLT products such as "paan" and "gutka" are common, and use may be normalized in South Asian cultures [31].

\section{Limitations}

Use of NHIS data has limitations in generalizing our findings to the entire Asian-American population due to self-reporting, sampling, and inclusion/exclusion criteria. NHIS is a self-reported cross-sectional nationally representative yearly survey, which asks participants about potentially stigmatized behaviors such as smoking and ATP use. As such, self-report may be limited by a social desirability bias and result in under-reporting of potentially stigmatizing conditions. While NHIS was intended to oversample minority groups, the Asian-American sample is undersampled relative to other groups, and may not be representative of the current demographic, given rapid growth in the past decade. Limited sample size as a result of undersampling restricted us from evaluating the three-way interactions between race/ethnicity, nativity, and sex in Asian Americans. As NHIS is conducted only in English and Spanish, non-English or Spanish-speaking Asian Americans were excluded, leading to an underrepresentation of smoking behaviors for this demographic [18]. The Sample Adult Core response rate from 20062014 ranged from around 60-70\% [32]. Although Asian Indians, Chinese, and Filipinos constitute some of the largest AsianAmerican ethnic groups, the publicly available NHIS dataset does not differentiate Koreans and Vietnamese due to their smaller numbers in the sample. However, Koreans and Vietnamese characteristically have high frequencies of tobacco use [5] and should be oversampled in future NHIS surveys. With only 3 years of ATP data in the NHIS supplement, our sample size was limited, and we can only report initial trends in ATP use, without any explanatory factors for use or non-use.

\section{Conclusion}

Our findings provide a comprehensive 10-year update on distinct smoking and tobacco use patterns in Asian Indians, Chinese, and Filipinos in comparison to the non-Hispanic White population in the USA. Filipinos stand out as the Asian group with the highest current smoking rates, with US-born and female Filipinos having uncharacteristically higher smoking rates compared to other Asian-American ethnic groups. Chinese are ideal to investigate for protective factors keeping rates of having ever used alternative tobacco products low; cessation and prevention programs can endeavor to replicate these factors to aid at-risk groups. Lowering short- and long-term health consequences from cigarettes and ATPs is a national health priority, and is more likely to be accomplished if done in a culturally tailored, precise manner, appropriate to the needs of specific ethnic groups. Considering that COVID-19 and other severe respiratory viruses disproportionately affect those with poor respiratory health [33], smokers, and marginalized communities of color [34], it is increasingly critical to lower current smoking rates in Asian Americans in a culturally targeted and nuanced fashion.

Supplementary Information The online version contains supplementary material available at https://doi.org/10.1007/s40615-021-01024-5.

Acknowledgments The authors thank Rishab Bhatt and Jaiveer Singh for their contributions to data analysis. Research reported in this publication was supported by the National Center for Advancing Translational Sciences of the National Institutes of Health under Award Number UL1TR003142. The content is solely the responsibility of the authors and does not necessarily represent the official views of the National Institutes of Health.

Code availability Upon request.

Funding This study was funded by the Stanford Center for Asian Health Research and Education (CARE). Research reported in this publication was supported by the National Center for Advancing Translational Sciences of the National Institutes of Health under Award Number UL1TR003142. The content is solely the responsibility of the authors and does not necessarily represent the official views of the National Institutes of Health.

Data Availability NHIS data are publicly available.

\section{Declarations}

Ethics approval This study is considered not human subjects research by the Stanford Institutional Review Board (IRB protocol \#57474). This article does not contain studies with human participants or animals performed by the authors.

Conflicts of interest The authors declare that they have no conflict of interest.

\section{References}

1. Lew R, Chen WW. Promising practices to eliminate tobacco disparities among Asian American, Native Hawaiian and Pacific Islander communities. Health Promot Pract. 2013;14(5_suppl): 6S-9S. https://doi.org/10.1177/1524839913497717.

2. NW 1615 L. St, Suite 800Washington, Inquiries D 20036USA202419-4300 | M-857-8562 | F-419-4372 | M. Modern Immigration Wave Brings 59 Million to U.S. Pew Research Center's Hispanic Trends Project. Published September 28, 2015. Accessed July 28, 2020. https://www.pewresearch.org/hispanic/2015/09/28/modernimmigration-wave-brings-59-million-to-u-s-driving-populationgrowth-and-change-through-2065/

3. NW 1615 L. St, Suite 800Washington, Inquiries D 20036USA202419-4300 | M-857-8562 | F-419-4372 | M. Key facts about Asian origin groups in the U.S. Pew Research Center. Accessed July 28, 
2020. https://www.pewresearch.org/fact-tank/2019/05/22/keyfacts-about-asian-origin-groups-in-the-u-s/

4. 6135_APPEAL_AsianAmerican factsheet_FINAL.pdf. Accessed August 26, 2020. https://appealforhealth.org/wp-content/uploads/ 2014/06/6135 APPEAL AsianAmerican factsheet FINAL.pdf

5. CDCTobaccoFree. Asian Americans, Native Hawaiians, Pacific Islanders and Tobacco Use. Centers for Disease Control and Prevention. Published August 28, 2018. Accessed August 2, 2020. https://www.cdc.gov/tobacco/disparities/asian-americans/ index.htm

6. Palaniappan LP. Araneta Maria Rosario G., Assimes Themistocles L., et al. Call to action: cardiovascular disease in Asian Americans. Circulation. 2010;122(12):1242-52. https://doi.org/10.1161/CIR. 0b013e3181f22af4.

7. Acoba J, Chen SA, Miller CF, Okazaki I. ACCC ADVISORY COMMITTEE. : 16

8. Mukherjea A, Wackowski OA, Lee YO, Delnevo CD. Asian American, Native Hawaiian and Pacific Islander tobacco use patterns. Am J Health Behav. 2014;38(3):362-9. https://doi.org/10. 5993/AJHB.38.3.5.

9. Creamer MR, Wang TW, Babb S, et al. Tobacco product use and cessation indicators among adults - United States, 2018. MMWR Morb Mortal Wkly Rep. 2019;68(45):1013-9. https://doi.org/10. 15585/mmwr.mm6845a2.

10. Maxwell AE, Bernaards CA, McCarthy WJ. Smoking prevalence and correlates among Chinese- and Filipino-American adults: findings from the 2001 California Health Interview Survey. Prev Med. 2005;41(2):693-9. https://doi.org/10.1016/j.ypmed.2005.01.014.

11. Chae DH, Gavin AR, Takeuchi DT. Smoking prevalence among Asian Americans: findings from the National Latino and Asian American Study (NLAAS). Public Health Rep. 2006;121(6):75563.

12. CDCTobaccoFree. Smokeless tobacco: health effects. Centers for Disease Control and Prevention. Published August 13, 2020. Accessed October 2, 2020. https://www.cdc.gov/tobacco/data statistics/fact sheets/smokeless/health effects/index.htm

13. Progress Erased: Youth Tobacco Use Increased During 2017-2018 CDC Online Newsroom | CDC. Published April 16, 2019. Accessed August 26, 2020. https://www.cdc.gov/media/releases/ 2019/p0211-youth-tobacco-use-increased.html

14. Yang T, Barnett R, Jiang S, Yu L, Xian H, Ying J, et al. Gender balance and its impact on male and female smoking rates in Chinese cities. Soc Sci Med. 2016;154:9-17. https://doi.org/10.1016/j. socscimed.2016.02.035.

15. Jha P, Jacob B, Gajalakshmi V, Gupta PC, Dhingra N, Kumar R, et al. A nationally representative case-control study of smoking and death in India. $N$ Engl J Med. 2008;358(11):1137-47. https://doi. org/10.1056/NEJMsa0707719.

16. NW 1615 L. St, Suite 800Washington, Inquiries D 20036USA202419-4300 | M-857-8562 | F-419-4372 | M. Chapter 1: Portrait of Asian Americans. Pew Research Center's Social \& Demographic Trends Project. Published June 19, 2012. Accessed February 14, 2021. https://www.pewresearch.org/social-trends/2012/06/19/ chapter-1-portrait-of-asian-americans/

17. NHIS - About the National Health Interview Survey. Published June 28, 2019. Accessed July 8, 2020. https://www.cdc.gov/nchs/ nhis/about nhis.htm

18. NHIS - 2018 Data Release. Published January 28, 2020. Accessed February 18, 2021. https://www.cdc.gov/nchs/nhis/nhis_2018 data release.htm

19. NHIS - Adult Tobacco Use - Glossary. Published May 10, 2019. Accessed July 30, 2020. https://www.cdc.gov/nchs/nhis/tobacco/ tobacco glossary.htm
20. CDCTobaccoFree. Asian Americans - Tips From Former Smokers. Centers for Disease Control and Prevention. Published March 31, 2020. Accessed August 2, 2020. https://www.cdc.gov/tobacco/ campaign/tips/groups/asian-american.html

21. quitlines appendix.pdf. Accessed August 9, 2020. https://www. cdc.gov/tobacco///quit_smoking/cessation/quitlines/pdfs/quitlines appendix.pdf

22. Maxwell AE, Garcia GM, Berman BA. Understanding tobacco use among Filipino American men. Nicotine Tob Res. 2007;9(7):76976. https://doi.org/10.1080/14622200701397890.

23. Schane RE, Ling PM, Glantz SA. Health effects of light and intermittent smoking: a review. Circulation. 2010;121(13):1518-22. https://doi.org/10.1161/CIRCULATIONAHA.109.904235.

24. Ni K, Wang B, Link AR, Sherman SE. Does smoking intensity predict cessation rates? A study of light-intermittent, light-daily, and heavy smokers enrolled in two telephone-based counseling interventions. Nicotine Tob Res Off J Soc Res Nicotine Tob. 2020;22(3):423-30. https://doi.org/10.1093/ntr/nty257.

25. An N, Cochran SD, Mays VM, McCarthy WJ. Influence of American acculturation on cigarette smoking behaviors among Asian American subpopulations in California. Nicotine Tob Res. 2008;10(4):579-87. https://doi.org/10.1080/14622200801979126.

26. Kuiper N. A National Asian-Language Smokers' Quitline United States, 2012-2014. Prev Chronic Dis. 2015;12. https:// doi.org/10.5888/pcd12.140584.

27. Tsoh JY, Burke NJ, Gildengorin G, Wong C, le K, Nguyen A, et al. A social network family-focused intervention to promote smoking cessation in Chinese and Vietnamese American male smokers: a feasibility study. Nicotine Tob Res. 2015;17(8):1029-38. https:// doi.org/10.1093/ntr/ntv088.

28. Feng G, Jiang Y, Li Q, Yong HH, Elton-Marshall T, Yang J, et al. Individual-level factors associated with intentions to quit smoking among adult smokers in six cities of China: findings from the ITC China Survey. Tob Control. 2010;19(Suppl 2):i6-i11. https://doi. org/10.1136/tc.2010.037093.

29. Mukherjea A, Modayil MV, Tong EK. Moving towards a true depiction of tobacco behavior among Asian Indians in California: prevalence and factors associated with cultural smokeless tobacco product use. Cancer. 2018;124(Suppl 7):1607-13. https://doi.org/ 10.1002/cncr.31102.

30. Get the Facts on E-cigarettes $\mid$ Know the Risks: E-cigarettes \& Young People | U.S. Surgeon General's Report. Know the Risks: E-Cigarettes and Young People | U.S. Surgeon General's Report. Accessed August 16, 2020. https://e-cigarettes.surgeongeneral.gov/ getthefacts.html

31. Sreeramareddy CT, Pradhan PMS, Mir IA, Sin S. Smoking and smokeless tobacco use in nine South and Southeast Asian countries: prevalence estimates and social determinants from Demographic and Health Surveys. Popul Health Metr. 2014;12(1):22. https:// doi.org/10.1186/s12963-014-0022-0.

32. Cynamon ML (CDC/OPHSS/NCHS). National Health Interview Survey : 10 .

33. CDC. Coronavirus Disease 2019 (COVID-19). Centers for Disease Control and Prevention. Published February 11, 2020. Accessed August 2, 2020. https://www.cdc.gov/coronavirus/2019-ncov/ need-extra-precautions/people-with-medical-conditions.html

34. CDC. Communities, Schools, Workplaces, \& Events. Centers for Disease Control and Prevention. Published April 30, 2020. Accessed August 2, 2020. https://www.cdc.gov/coronavirus/2019ncov/community/health-equity/race-ethnicity.html

Publisher's Note Springer Nature remains neutral with regard to jurisdictional claims in published maps and institutional affiliations. 